\title{
Revisitando a Escola Inglesa
}

Revisiting the English School

JOSÉ FLÁVIO SOMBRA SARAIVA*

Rev. Bras. Polít. Int. 49 (1): 131-138 [2006]

\section{Introdução}

O objetivo deste artigo é o de revisitar a Escola Inglesa das Relações Internacionais a partir da chegada de novos textos de reflexão a respeito do seu lugar na teoria e na historiografia das relaçōes internacionais. Passará em revista quatro aspectos: a revalorização da Escola Inglesa no contexto de ebulição teórica e histórica do momento no estudo das relações internacionais; o esforço de busca de ontologia própria da Escola Inglesa por meio da noção de middlecourse; as contribuições mais recentes de Dunne e Vigezzi na avaliação do papel da escola inglesa; e, uma breve conclusão desde o Sul.

\section{Uma escola contra a polarização ideológica da Guerra Fria}

A difusão de teorias e historiografias contemporâneas das relações internacionais - enquanto produto das condições ambientais que as animam, conferem vivacidade, exuberância política e eloqüência heurística - não é fenômeno uniforme e universalizável. Autores da Escola de Frankfurt, em algumas de suas críticas às condições sociais da produção do conhecimento científico, chamam a atenção para a invisibilidade em torno da qual certas tradiçóes são descartadas pelo mainstream. Um caso emblemático é certamente a indiferença generalizada em relação às percepções, textos e construções conceituais que conduziram à formação da Escola Inglesa das Relaçóes Internacionais.

Redescoberta na passagem dos anos 1980 para o início da década passada, a Escola Inglesa havia permanecido nas três décadas anteriores como água morna, um não-dito na história do pensamento atinente às relações internacionais e um albergue espanhol onde todos depositavam e retiravam

\footnotetext{
* Professor do Instituto de Relaçôes Internacionais da Universidade de Brasília - iREL-UnB e diretorgeral do Instituto Brasileiro de Relações Internacionais - IBRI (fsaraiva@unb.br).
} 
seus próprios apetrechos intelectivos para as relações internacionais. Autores como Martin Wight, ${ }^{1}$ Hedley Bull ${ }^{2}$ ou Adam Watson ${ }^{3}$ eram capturados para taxonomias que os incluíam em tradições anglo-saxônicas abrangentes, ora nas vertentes realistas e outras vezes nas tradiçôes liberais ou historicistas.

Para a escola inglesa, passar desapercebida significava não estar nas grandes estantes da formação escolástica, quase canônina, e que viria a predominar na difusão das teorias realistas e liberais no pós-Segunda Guerra Mundial. Ao não servirem muito ao complexo conhecimento-política externa-poder estratégico norte-americano na Guerra Fria, a Escola Inglesa foi preterida em favor das teorias do poder racional e pela soberania crescente das escolas norteamericanas. Da mesma forma, as contribuiçôes inglesas viriam ser obliteradas pela grande difusão da filosofia e da sociologia política das relações internacionais de corte europeu continental inspiradas em Aron e Merle.

No caso norte-americano, a imposição de um único olhar ao Ocidente, plasmado pela esquizofrenia ideológica da Guerra Fria, levaria a que as relações internacionais se dividissem, como campo de reflexão, entre falsas antinomias: o realismo racionalista contra o idealismo romântico; a contenção ao comunismo pela realpolitik contra o liberalismo universalista cooperativo; o caminho da liberdade gerenciada pela hegemonia norte-americana contra os românticos dos movimentos anti-hegemônicos. A incapacidade de apurar os fenômenos da descolonização afro-asiática e a miopia conceitual que impedia observar a crescente flexibilização da ordem bipolar já nos anos 50 dificultavam a ampliação do escopo intelectual das relaçôes internacionais. Foi necessário que a Guerra Fria se encerrasse para que os grandes autores norte-americanas e seus discípulos percebessem isso, como lembra John Gaddis ${ }^{4}$.

A bipolaridade mental nas percepções que guiaram o nascimento de instituiçōes acadêmicas dedicadas às relaçōes internacionais nos Estados Unidos dos anos 50 aos anos 70, associada ao poder econômico e seus recursos para a implantação de plataformas de conhecimento voltadas para o monitoramento do mundo e para o reforço da capacidade de agir dos Estados Unidos como herdeiro natural da hegemonia européia, excluíram uma via do meio na análise das relaçôes internacionais, um certo middle-course nas investigações atinentes às coisas do mundo. Isso explica porque a escola inglesa, apenas em fins dos anos 80 e início dos 90, foi finalmente apartada das tradiçôes anglo-saxônicas como um conjunto orgânico e próprio. Daí sua importância crescente nos estudos dos politólogos e historiadores das relações internacionais.

\footnotetext{
1 WIGHT, Martin, A política do poder. Brasília: Editora da UnB, 2004.

2 BULL, Hedley, A sociedade anárquica. Brasília: Editora da UnB, 2002.

3 WATSON, Adam, The evolution of international society: A comparative historical analysis. London: Routledge, 1992.

4 GADDIS, John. We now know. Rethinking Cold War history. Oxford: Oxford University Press, 1998.
} 


\section{O valor do middle-course}

$\mathrm{O}$ que é o middle-course? É a possibilidade de que as antinomias sejam contidas por meio de formas intermediárias, menos radicais sob o ponto de vista intelectual e político, menos apaixonadas pela Guerra Fria e talvez mais saudosa da velha hegemonia européia do século XIX. É esse o espaço intelectual explorado pela Escola Inglesa de Relações Internacionais.

A relevância específica da Escola Inglesa reside nesse meio-termo, bastante satisfatório para o enfrentamento das árduas questões conceituais e práticas em torno das quais se debruça o pesquisador das relações internacionais no mundo atual. Lutando para manter à tona formas divergentes de análise, de discussão e de abordagem, a Escola Inglesa ensaiou forma de ver as relações internacionais mais condizente com as ondas de desconfiança do racionalismo e mais próxima à voga do construtivismo social. A relativa displicência em relação à necessidade de escolha de uma tradição ou de uma teoria específica para compreender a realidade e o esforço de buscar uma abordagem pluralista são, sem dúvida, suas maiores contribuições, embora certamente possa ser essa também uma de suas fraquezas.

No entanto, a Escola Inglesa buscou seu próprio caminho para se constituir ela mesma uma tradição própria. Situando-se entre o racionalismo realista e o neoliberalismo institucionalista de corte norte-americano, a Escola Inglesa nega as premissas e as interpretações do realismo e aproxima o entendimento das relações internacionais do que hoje é reconhecido pelo construtivismo social como o papel das idéias, das identidades como construtores de interesses. Em alguma medida, teóricos construtivistas norte-americanos como Ruggie, Onuf e Wendt bem como os europeus, como Weaver, Kissolewski e Jorgensen seguem, de forma explícita ou implícita, uma linhagem de problemas cognitivos sugeridos pelos autores clássicos da Escola Inglesa.

A rejeição dos prismas extremos, do realismo e sua obsessão pelo poder ao idealismo utopiano e seu clamor por mudanças, é um traço do meio-termo incessantemente procurado pelos autores da escola inglesa. A incorporação desse middle-course seria, em outras palavras, a resultante da confrontação entre a práxis política dos Estados com uma política alternativa ideal. Demandas práticas e clamores morais devem vir juntos, sob pena de um, ao sobrepor-se ao outro, impedir a dimensão regulatória das relações internacionais.

Daí a emergência de conceitos centrais como o de sociedade internacional, sistema internacional e sociedade global. Esses conceitos não são estanques, abstratos no sentido da sua institucionalização. Ao contrário, a sociedade internacional é uma estrutura histórica e culturalmente determinada, resultante da interação de atores, originada das práticas que determinam o comportamento dos Estados, mas em interação permanente para dentro e para fora deles mesmos. Mesmo as instituições da sociedade internacional, sustentadas em normas e valores comuns, são cultural e historicamente determinadas. 


\section{Duas visitas à Escola Inglesa: entre Dunne e Vigezzi}

Duas obras, ainda não resenhadas no Brasil, são essenciais à visão de conjunto da Escola Inglesa. A primeira, obra fundamental do estudioso britânico que renovou os debates iniciais mantidos por Roy Jones, Peter Wilson, Sheila Gradder e Barry Buzan, é o livro de Tim Dunne. ${ }^{5}$ A segunda, que acaba de sair, é o livro de despedida do historiador italiano Brunello Vigezzi. ${ }^{6}$

Tim Dunne faz uma viagem completa na história das obras e arquétipos propostos pelos autores essenciais da Escola Inglesa. Inicia por Carr, para sugerir o quanto teria agido como o fantasma que povoaria a imaginação dos debates posteriores da Escola Inglesa nas décadas seguintes à difusão da sua obra seminal. ${ }^{7}$ Um precursor, mas também um outsider em relação aos desdobramos posteriores da Escola Inglesa, Carr seria mais um ativista intelectual que um teórico internacionalista.

Centro das querelas intelectuais nos primeiros grandes debates epistemológicos das relações internacionais, Carr reagiu tanto às "ameaças" liberais quanto ao realismo que levaria a Morghenthau. Sua idéia de valorização da idéia de comunidade política e da ampliação das obrigações morais na política internacional superavam, de vez, a antinomia que muitos tentaram amarrar Carr entre o realismo e o idealismo. Daí a dupla atração de Carr pelos pós-modernistas de hoje: fez extraordinário escrutínio do conceito de poder, mas também do pragmatismo.

Wight, em Dunne, é estudado como o autor da grande contribuição histórica à Escola Inglesa. Preocupado em estudar a idéia de sistema de estados e de formular questōes e proposiçōes que permitissem estudos comparados do sistema europeu com outros sistemas históricos, Wight foi pioneiro nessa área. Para Wight, estudá-los e compará-los era obrigação, mas estabelecer dicotomia ou noçôes de superioridade de um sistema sobre o outro não era saudável.

Dunne chama a atenção para o fato de que, como Carr, Whight foi capturado também pela "teoria geral" do mainstream norte-americano, embora não tivesse nada com os desdobramentos que deram a seus ensinamentos. Para Barry Buzan e Richard Little, há uma dimensão rara em Wight que era sua extraordinária capacidade de tratar e caracterizar as mais diferentes arenas políticas como sistemas internacionais. Tal era o caso do caleidoscópio político por ele apresentado da era helenística e grega, que parecia moderna aos olhos dos seus alunos, ao passo que grande parte da unidade cristã do mundo medieval parecia remota e estranha.

5 DUNNE, Tim. Inventing international society: a history of the English school. London: Macmillan, 1989.

${ }^{6}$ VIGEZZI, Brunello, The British Committee on the Theory of International Politics (1954-1985): The rediscovery of History. Milano: Unicopli, 2005.

7 CARR, Edward H., Vinte anos de crise (1919-1939). Brasília: Editora da UnB, 2001. 
Essa capacidade de ir e vir na história seguiu, em alguma medida, na obra de Adam Watson, que não estudado por Dunne, manteve os passos de Wight na sua obra fundamental dedicada à evolução da sociedade internacional. Para Watson, que como Wight dirigiu o British Committee on the Theory of International Politics, o que importa é concentrar os esforços na comparação da natureza e no funcionamento dos sistemas de estados historicamente estabelecidos.

Wight foi, de fato, para a Escola Inglesa, o seu godfather. Superou o debate dicotômico da Guerra Fria entre realistas e idealistas, propôs a separação entre a teoria política clássica e a teoria e a história das relações internacionais, estabeleceu as premissas do caminho do meio mais próximo aos preceitos grocianos e inaugurou a análise em torno do sistema de estados. Militou Wight na preparação de boa base conceitual para os debates que se seguiram na Escola Inglesa até os anos recentes, deixando pouco texto escrito e muitas anotaçōes de aulas que foram transformadas em roteiros de livros senão em manuais, como no caso do seu Systems of States, editado depois mesmo de sua morte e publicado por Hedley Bull.

A propósito de Bull, Dunne o vê como um "constant borrower" de Wight, ao ponto de atribuir ao último o papel de mentor. Estaria em Hedley Bull três incontestáveis contribuiçōes de Wight: a busca de padrōes, na história das idéias, úteis às relações internacionais; a eqüidistância em relação ao shorttermism da política exterior; e a incessante pesquisa em torno das bases normativas da sociedade internacional em temos comparativos.

A concepção pluralista do sucessor de Martin Wight é positivamente avaliada por Dunne. Hedley Bull provê uma ordem internacional tolerante, fundada no consenso limitado; enfatiza a força do pluralismo que permite mediar entre a negação realista da sociedade internacional e a assunção legal da existência, a priori, da mesma; e inclui a dimensão da justiça como um valor na sociedade internacional, sem desmerecer a dimensão da ordem.

É Bull o mais preocupado da Escola Inglesa com a polarização ideológica da sociedade internacional pós-1945. Para ele, a sociedade internacional pluralista estava em xeque ante a Guerra Fria e suas implicações globais. Híbrido de duas culturas, a das tradições liberais constitucionalistas e a das posições bastante diferenciadas em relação aos temas do mundo do pós-guerra, Bull é mais cauteloso que Wight e menos interessado na hermenêutica da conversação entre filósofos e práticos ou na origem das normas e valores nos sistemas de estados.

Bull está menos interessado em saber se um chefe de estado ou um negociador externo é grociano ou maquiavélico. O que interessa para esse autor é como as práticas podem ser identificadas na sociedade internacional contemporânea. O tais três " $\mathrm{r}$ " - racionalismo, realismo e revolucionismo apenas teriam sentido se encapsulados por padrões existentes nas relações internacionais. Sua noção de sociedade anárquica, portanto, oscila entre o tratamento mais restritivo da concepção grociana da sociedade internacional e 
as visões normativas de Wight. Bull é, sem dúvida, o autor da via média entre a escolástica do British Committee e o cientificismo behaviorista; "a blend of intelligent social science and humanism", com lembraria Stanley Hoffmann.

Depois de Dunne, o segundo grande livro acerca da Escola Inglesa é escrito fora da Inglaterra e lançado em fins de 2005. Historiador de peso no desenvolvimento da história das relações internacionais, Vigezzi encerrou sua carreira acadêmica e aposentou-se das quatro décadas nas quais atuou o Centro per gli Studi di Política Estera e Opinione Pubblica em Milão. Depois de traduzir para o italiano a obra conjunta organizada por Bull e Watson, ${ }^{8}$ Vigezzi vinha se dedicando a estudar, de forma sistemática, os debates e os textos de formação e desenvolvimento do British Committee on the Theory of International Politics.

Vigezzi produz obra definitiva, de 440 páginas bem construídas em torno da evolução histórica do British Committee na temporalidade que vai de 1954 a 1985. As três décadas de debates estão organizadas em torno de três grandes partes do livro. Na primeira, a comparação conceitual entre sistema e sociedade internacional é avaliada na trajetória do British Committee. Ganha força especialmente a dimensão da contribuição histórica da Escola Inglesa e os interessantes embates entre Bull e Watson a respeito da pertinência, limites e possibilidades da aplicação do conceito de sociedade internacional para as relações internacionais extra-européias.

A segunda parte do livro de Vigezzi concentra-se, de fato, na evolução histórica do British Committee, do seu nascimento, passando pela fase de busca de fundamentos e conceitos, até a forja do conceito de sociedade internacional na acepção a qual a Escola Inglesa tanto se esmerou. Segue a segunda parte tratando das especificidades das relações entre a história e a teoria e sua indissolubilidade para o estudo do campo atinente às relaçóes internacionais. O desafio da ética e o tema da expansão da sociedade internacional alcançam destaque especial nessa parte do livro.

Finalmente, na terceira e última parte do livro, e ao contrário de Dunne, Vigezzi utiliza uma gama extraordinária de documentos primários das discussōes, papers, publicização das reuniōes e lista de participantes das reuniōes do British Committte. Munido de muitos documentos, como fotos e listas de presença, Vigezzi desvenda o visível na invisibilidade que marcava a emergência do conceito de sociedade internacional. Curioso é o documento da página 395 no qual o relator dos debates entre Wight e Bull em outubro de 1961 registra: "Wight and Bull in their respective papers were agreed in holding that there is an international society; and no one, in the course of the discussion, questioned this view. For different people, however, the term meant different things." 9

\footnotetext{
8 WATSON, Adam \& BULL, Hedley, The expansion of international society. Oxford: Oxford University Press, 1984.

${ }^{9}$ VIGEZZI, Brunello, op. cit., p. 395.
} 


\section{À guisa de conclusão: uma incipiente visita do Sul}

É ululante que a Escola Inglesa necessita ser revisitada. Foi o que se procurou nessa nota, na qual dois livros de colegas europeus fazem o dever de casa. Esse gesto, quase tardia diante da alternativa de interpretação que essa escola ofereceu às relaçóes internacionais da Guerra Fria, merece ser reconhecido.

Relevante que a última obra de um dos maiores historiadores das relaçôes internacionais contemporâneas e durante muitos anos presidente da Comissão Internacional de História das Relações Internacioanis, Brunello Vigezzi, tenha tido como objeto justamente essa alternativa de leitura dos fenômenos internacionais. Com a sua reconsideração, encerra-se de vez a noção imprudente, ainda bastante difundida nos manuais de relações internacionais, de que há uma tradição anglo-saxônica das relaçôes internacionais única. Os ingleses da Escola Inglesa não compuseram a tradição norte-americana tal qual sugerida por parte das taxonomias das escolas apresentadas em manuais acadêmicos bastante difundidos. Nem a captura de autores como Carr ou Wight foi feliz para sistemas de proposições fora da Escola Inglesa.

A redescoberta da Escola Inglesa, no momento no qual o construtivismo social é voga intelectual nas relações internacionais, é particularmente interessante também. Reforça a idéia de que é possível uma certa conversação entre escolas e proposições anteriores com aquelas às quais estamos mais ligados como geração mais recente de estudiosos dos temas internacionais.

No Sul, fica uma questão: qual a utilidade desses esquemas teóricos para o caminho da construção de uma ontologia própria? Pergunta inquietante, talvez a construção da Escola Inglesa nos sirva como um exemplo de que o subdesenvolvimento mental e a reprodução pouco crítica dos cânones nem sempre são úteis às especificidades do nosso entorno. E talvez o melhor exemplo do caso inglês seja o fato de que é estimulante inventar e criar conceitos que emanam de percepções e estudos de problemas novos e realidades próprias que nos cercam. Há algo em comum entre a Escola Inglesa e o esforço de adensamento de uma tradição, por exemplo, argentino-brasileira, ou mesmo latino-americana, em torno das relaçóes internacionais contemporâneas da inserção da região no contexto global.

Finalmente, a noção mesma de sociedade internacional, no espectro normativo sugerido pelos ingleses, parece ter baixa aplicação prática ao ambiente internacional no qual estamos vivendo. Uma sociedade internacional esgarçada pelos egoísmos nacionais, a crise do multilateralismo e da capacidade de regulação internacional, a descrença na ética e no solidarismo, as novas formas de guerras internacionais malthusianas, entre outros fatos, parecem inibir uma nova sociedade internacional à moda da Escola Inglesa.

Recebido em 4 de abril de 2006 Aprovado em $1^{\circ}$ de junho de 2006 


\section{Resumo}

Neste artigo se tem como objetivo avaliar criticamente a evolução recente da Escola Inglesa das Relações Internacionais, procurando situá-la no espectro mais amplo do debate interparadigmático da disciplina.

\section{Abstract}

The article aims to analyze critically the recent evolution of the English School of International Relations, according to the debate of the discipline.

Palavras-chave: Escola Inglesa, Teoria das Relações Internacionais, História das Relações Internacionais

Key words: English School, Theory of International Relations, History of International Relations 